\title{
Verlierer ist die Altenpflege
}

\author{
Mit Hochdruck will die Bundesregierung die drei getrennten Ausbildun- \\ gen in der Pflege zu einer generalistischen Ausbildung verschmelzen. \\ Damit würde ein gut funktionierendes System ohne Not zerstört.
}

_ Mehr als eine Million Menschen arbeiten in Deutschland in der Pflege. 300.000 von ihnen sind examinierte Fachkräfte mit einer hochwertigen Ausbildung. Die Bundesregierung will nun die bislang getrennten, jeweils dreijährigen Ausbildungen in der Altenpflege, der Kinderkrankenpflege und der Krankenhauspflege ab $2018 \mathrm{zu}$ einer einzigen, "generalistischen“ Ausbildung verschmelzen.

Dagegen gibt es vonseiten der der Kinderkrankenpflege, vor allem aber aus der Profession der Altenpflege massiven Widerstand. Denn die jetzt vorliegenden Eckpunkte der neuen Einheitsausbildung zum Pflegefachmann bzw. zur Pflegefachfrau gingen leider klar zulasten der Altenpflege - und damit letztlich auch zulasten pflegebedürftiger alter Menschen. Das bisherige Ausbildungssystem der Altenpflege hat sich bewährt, ist doch die Qualität der Pflegearbeit anerkannt hoch. Auch entdecken seit einigen Jahren immer mehr junge Menschen die Altenpflege für sich als spannenden Beruf - allen Unkenrufen gerade in den Medien zum Trotz. 2015/16 beginnen 28.000 junge Menschen ihre Altenpflegeausbildung, insgesamt gibt es fast 70.000 Azubis.

Die geplante generalistische Ausbildung wird organisatorisch kompliziert. Alle angehenden Pflegenden sollen viele Stationen durchlaufen: Akutpflege im Krankenhaus, Langzeitpflege in einer Pflegeeinrichtung, ambulanter Dienst, Kinderkrankenpflege, Pädiatrie und Psychiatrie, Pflegeberatung, Palliation und Rehabilitation. Angehende Altenpfleger verbringen dann im praktischen Ausbildungsteil nur halb so viel Zeit in ihrer Stamm-Pflegeeinrichtung wie heute. Und auch die Auszubildenden in der Kinderkrankenpflege oder der Krankenhauspflege durchlaufen diesen ,Wanderzirkus“, was in die Einrichtungen der Altenpflege enorme Unruhe durch ständig neue Gesichter trägt.

\section{Viel Mehrarbeit für Pflegedienste}

Auch auf die Einrichtung, die den Ausbildungsvertrag geschlossen hat, kommt viel Arbeit zu. Sie ist für die gesamte praktische Ausbildung in allen Ausbildungsstätten verantwortlich und muss diese zentral organisieren. Das gilt auch für die Finanzierungsströme, die die verschiedenen Stationen betreffen. Die vielen kleinen und mittleren Unternehmen werden sich bei einem derartigen Aufwand die Ausbildung kaum noch leisten können.

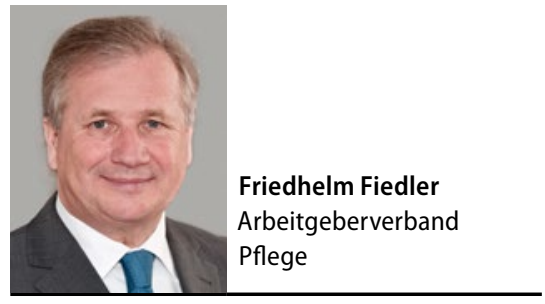

Ein weiterer Kritikpunkt: Der theoretische Ausbildungsteil wird weiter kräftig hochgeschraubt, sodass Hauptschüler, die einen beachtlichen Teil der Altenpflegeschüler ausmachen, es schwer haben werden. Ohne das Potenzial der Hauptschüler aber droht ein echter Personalnotstand in der Altenpflege.

Die Deutsche Gesellschaft für Gerontopsychiatrie hat kürzlich 8.000 Altenpflegeschüler umfangreich befragt. Ein Ergebnis war: $37 \%$ hätten keine Ausbildung begonnen, wenn diese bereits generalistisch ausgerichtet gewesen wäre. Und immerhin 19\% würden nach einer generalistischen Ausbildung in die Krankenpflege wechseln. Für die Altenpflege in Deutschland eine wahrlich dramatische Perspektive.

- Der Autor ist Vizepräsident des Arbeitgeberverbands Pflege

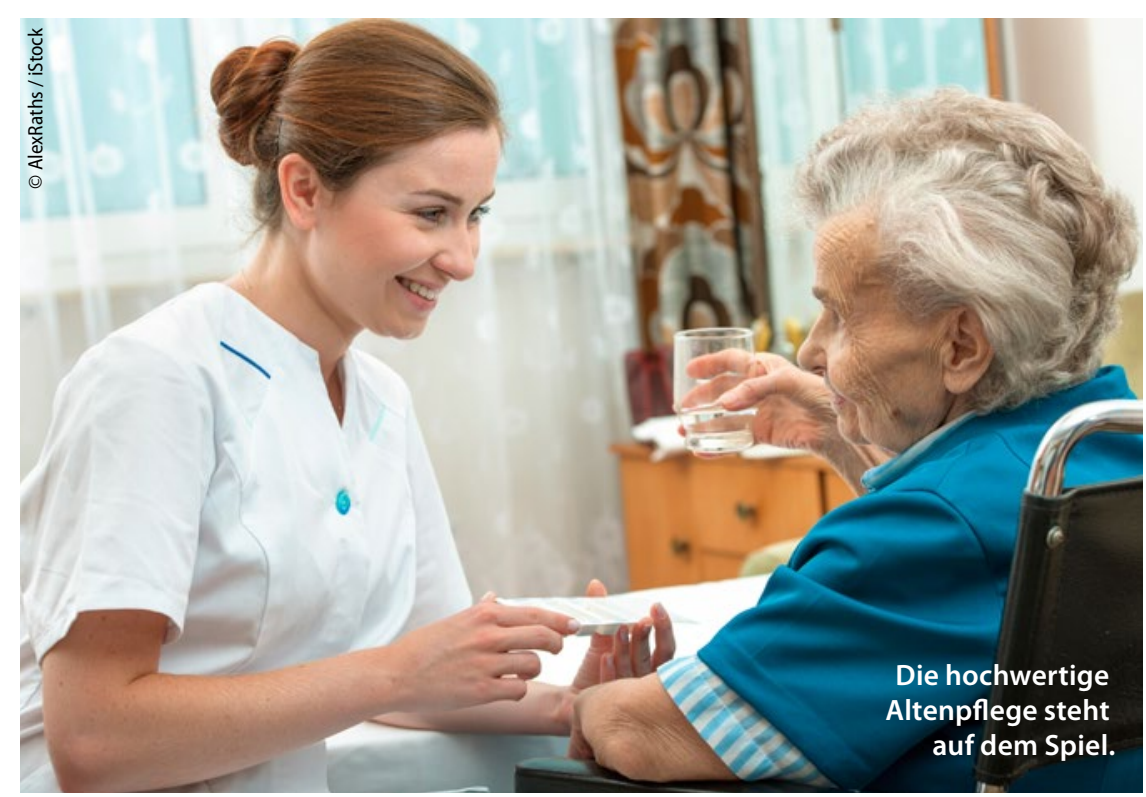

